\title{
THE DIMENSIONS OF HUMAN ACTION AND \\ PROPERTY
}

\author{
GARRICK SMALL \\ University of Technology, Sydney
}

\begin{abstract}
This paper adds depth to the question of property theory in the face of recent challenges, including the demise of socialism as a global ideological political force and the rise of recognition of customary property rights. It examines the dynamics of human action using a sociological/anthropological approach to review the appropriate treatment of property within society.
\end{abstract}

The modern Western tendency to reduce all politico/economic systems onto a single continuum between the ideologically Left and Right is reviewed and found to rest on a single anthropological assumption of dubious merit. There is ample evidence of other anthropologies that result in successful cultural institutions well beyond the modern left/right dichotomy. Cultural choice of anthropology is linked to beliefs regarding family, tradition and spirituality. Of these, spirituality is selected as the fundamental driver.

Three dimensions of human action proceed from this analysis, the political/economic institutional dimension, the anthropological dimension and the spiritual, or metaphysical, dimension. Some implications for the institution of property are examined to conclude that combined, they provide a more robust framework for understanding property than the one-dimensional approach implicit in modernity.

Keywords: Property, human action, motivation, anthropology, political economy, economic behaviour, altruism, spirituality, metaphysics.

\section{INTRODUCTION}

Customary people view property in a way that integrates it into their overall culture and spirituality (Small, 1997), whereas Western people tend to use it as the basis for the construction of their culture in terms that are primarily economic (Cuff et al., 1990). In the West, property is perceived as a bundle of positive legal rights that are politically based and valued in commercial terms (Macpherson, 1978). Customary people understand property as essentially proceeding from their spirituality and valued in relational, almost familial, terms (Ezigbalike, 1994). When Western 
people are confronted with customary understandings of property, they are forced to grapple with elements of culture that they usually keep quite distinct from property. Property, to the Western mind, is the basis of commerce, and commerce is the material support for all the other institutions that comprise culture. Smith established the Western understanding of property as an arbitrary institution visible only as those conventions regarding ownership that are upheld by the power of the state (Smith, 1778/1910). On this basis, property has no necessary connection with other cultural forces, beyond the chance historical events that may have contributed to its current form.

The purpose of this paper is to locate property more completely within the realm of human social action. To do this, the dominant dimensions of human action will be unpacked and these will be used to develop a framework for understanding property within Western and customary cultures. It is argued that while Western people stress institutional issues regarding property, these only comprise one limited dimension of human action and the position rests on unstated assumptions regarding other critical issues. The paper attempts to demonstrate the importance of these other dimensions of human action that impact on property to provide a better balanced analytical perspective, suitable for exploring property outside of Western modernity.

\section{THE FOUNDATIONS OF PROPERTY ECONOMICS}

Property economics can be considered to be the study of how to use property most profitably. Implicit in its parameters is the concept of property. To the Western mind, this is a statement of the obvious, but the concept of property becomes problematic when it is exported to other cultures. The positive concept of property is grounded on the set of private rights that the state will uphold regarding property using the force of law. Property therefore has as its foundation, the system of law and government that prevails in a particular society. Property, law and government may be considered to comprise the public institutions of a society. While property rests on the legal/governmental framework, the latter is not the ultimate origin of human action.

The primary sources of English law are statute and common law precedent; both have a single origin. Common law is the crystallisation into law of the ethical position of the common person (Devlin, 1965). Statute law is the determination of the government enshrined in positive acts that acquire the force of law through the authority of the government. In a democracy, the government takes its authority from the free choice of the people who elect representatives who will legislate in accordance with their opinions regarding management of the society. This means that the people vote for representatives who will act according to their cultural and 
ethical values. In both common law and democratic government enacting statute, the ultimate sources of action are the cultural and ethical values of the people.

\section{Figure 1: Foundations of property economics}

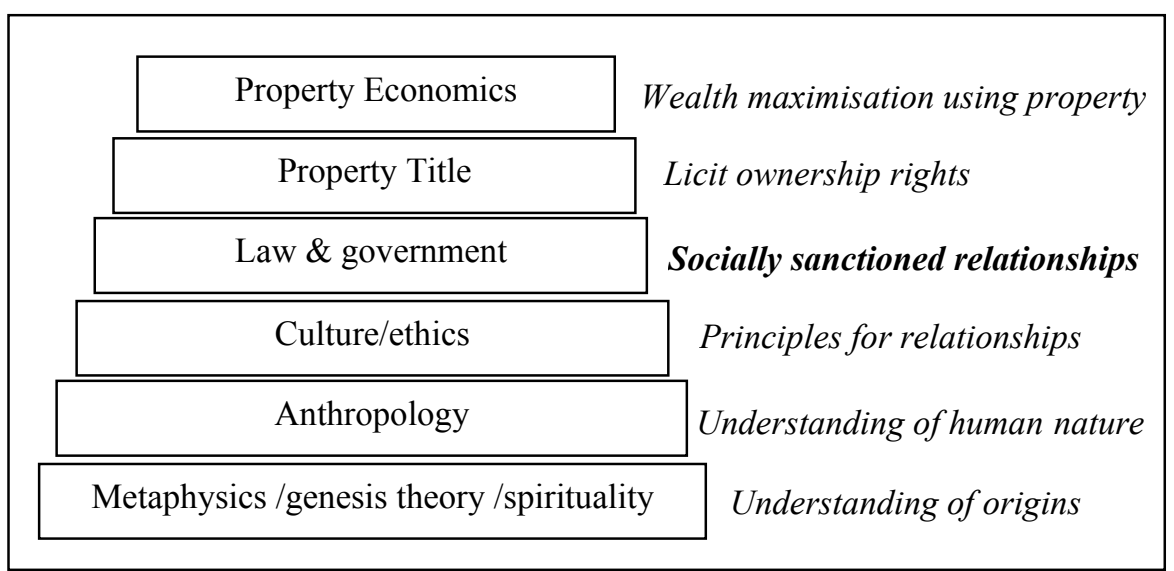

Cultural and ethical values vary substantially between various societies. Their origins may be traced to many sources, but the dominant immediate foundation is the theory of human nature that dominates in that society. Every person carries an implicit theory of what other people are like, and how they should be related to; this theory is sometimes called an anthropology. A person's theory of what others are like determines whether others should be trusted or not, whether they should be respected or not, even whether they should be exploited or not. An individual's anthropology may include differing categories of others to whom differing approaches are appropriate. In many cultures, the treatment of blood relatives is different to outsiders. In some, outsiders are treated in a different way on the basis of religion, physical appearance or race. Often, outsiders are treated worse than insiders, but in many cases, the individual takes licence with insiders while showing greater respect to outsiders. For example, in some customary cultures, personal property is only loosely upheld within the tribe or clan, while great respect is shown to Westerners. The point is that culture and ethics, even when they appear to be linked to tradition or other sources, are proximately grounded on the individual's anthropology, especially as this is corporately shared across a society.

An anthropology may be adapted from a society's traditions by the individual, but it is still ultimately grounded on more fundamental issues. Most customary cultures are very conscious that their ways of life are ultimately grounded on their origins. Discussion of property invariably includes discussion of spirituality. Spirituality includes a story of creation, of the origin of the land and the people and a 
relationship between the creator and the people. The beliefs of a people regarding their origins form both the basis of their anthropology and the basis of their understanding of property. In philosophy, the study of the origins of existence is metaphysics. In the Western tradition, metaphysics does not necessarily include theology, although it often intersects with it (Johnson, 1995).

The beliefs of a people, or an individual, regarding the origin of things does not have a basis in any other aspect of human understanding. Aristotle held that metaphysics was the first science, the beginnings of understanding upon which all other understanding, all the other sciences, were built. The case of customary people and their relationship to land is no more than a specific illustration of Aristotle's position.

This means that property economics may be considered to stand on an ordered set of foundations that reach back to the very basis of human reason and belief. This may be illustrated as shown in Figure 1. This set of foundations can be seen to influence human action at various levels. It is highly culturally specific. Using it, the various dimensions of human action can be examined and the interrelationship between Western and non-Western cultures can be explored.

\section{PROPERTY AND CULTURE}

Marx focused on the fundamental nature of economic relations in the construction of a culture and described society as consisting of an economic base upon which all other cultural institutions were built. The economic base/superstructure model of society is probably a fair construction of human society, if existence is assumed to be no more than material. It is consistent with the Enlightenment view of the world and humanity. The Enlightenment viewed all social institutions as arbitrary and lauded human freedom their only licit origin (Hume, 1777/1975; Smith, 1778/1910). The pre-eminence of freedom in Enlightenment thought meant that no appeal could be made to normative ethical values or religious directives in framing social institutions unless they were generally accepted. Community opinion and practice is the ultimate reference point. While this approach has the capacity to deliver ethically sound and even religiously inspired outcomes, they remain subject to the veto of human opinion. That is, human preference is the highest authority. This position has become a foundation piece of modern democratic thought, though in practice, it means the human preference of those with effective political power.

Following Smith's notion that property is the outcome of a purely positive ${ }^{1}$ statutory situation, it is easy to recognise that property in Western thought is closely connected with other manifestations of government, all of which are ultimately the

${ }^{1}$ Positive in this context means arbitrary. 
result of arbitrary expressions of human preference. The advantage of this position is that it has the power to accommodate a range of diverse values within a single society on the assumption that public dialogue, common sense and democratic government will combine to bring to the fore the best available choice for government at a particular time.

Implicitly, the Western theory of government also relies on commonly held views regarding a number of other important issues. These include:

i. The assumption that political power finds its zenith in the democratically elected body of representatives that comprises government.

ii. The assumption that those who control effective political power will use it for what is best for society when making political decisions.

iii. The assumption that society is an association of independent free individuals who recognise the benefits of co-operative social organisation.

iv. The assumption that there does not exist an objective knowable set of principles that could be used as a basis for any society's ethical scheme, or public policy.

v. The assumption that spiritual/religious beliefs should be relegated to the private forum as a personal subjective influence over the individual of dubious merit for the formation of public policy.

vi. The assumption that people are primarily responsible for themselves alone and that there are minimal necessary obligations to the other in relationship, beyond what is sanctioned by public policy (statute).

These assumptions constitute a theory of human nature and social relationship. Such a theory can be referred to as an anthropology. This one is correctly termed the Enlightenment anthropology, or more generally, the modern anthropology. A person's theory of the nature of others in society determines in large measure the person's personal choices in dealing with them. That is to say, it is sufficient as a basis for an ethic. This is quite independent of the coercive influence of government.

Strictly speaking, property is not necessarily directly influenced by the dominant anthropological theory of a society, though it may well be indirectly affected. A person's anthropological beliefs will influence that person's exercise of political power when it comes to determining the nature of property, just as it influences the direction of other aspects of public policy. Hence, if the person believes that human relations are not governed by spiritual beliefs, that person will not support legislation inspired by the teachings of Christianity, Islam or other religious traditions. On the other hand, if the person believes that humans have an obligation to future generations, who by nature are currently politically powerless, that person may support controls on property, such as environmental limitations. 
A particular anthropology does not necessarily translate into a single system of public policy. Rather, it provides underlying principles that particular policy formulations must embody that may lead to very different institutional outcomes. Nowhere is this more apparent than in the case of religious sentiment and governmental organisation. Historically, both Whig and Tory extremes of British politics espoused Christian foundations. Today, the US Republican party tends to be overtly Christian; while in Australia, at the other ideological pole, the Australian Labor Party has long links with Irish Catholics.

\section{THE INSTITUTIONAL DIMENSION OF PROPERTY}

Likewise, the Enlightenment anthropology has given rise to two diametrically opposed property institutions, those of liberal capitalism and communist socialism. Both embody Enlightenment liberalism, though that liberalism itself manifests as the foundation of the two polar extremes. British liberalism is associated with liberal capitalism, now evident in the neo-conservative movement, while American liberalism is associated with left wing ideology that finds its zenith in Marxist socialism. Within this anthropology, it is common for the Western mind to try to locate everyone somewhere on a continuum between these commonly accepted extremes. People are usually evaluated as either politically left or right, socialist or free market, big government or small government. The Leftist, socialist, statist person is assumed to be suspicious of private property, while the right wing, liberal capitalist will pursue private property as a vital component of the liberal capitalist panacea for all economic and most social problems.

Other positions are perceived to be mixtures of the two, usually judged to be nearer to one or other pole. The mixed economies that have dominated in the West over much of the last half-century attempted to moderate the shortcomings of both extremes through a centre-position compromise. One of their shortfalls is that despite pragmatically recognising the hazards of both extremes, they do not provide a convincing theory of why a mixed position should be superior. Referred to as third way economic theories, they usually adopt the same basic anthropological parameters as the extremes to the left and right, with the distinction that they attract criticism from both poles. Roepke $(1937 / 94,1948 / 1996)$ is representative of an economic theorist advocating third way economies. Roepke's writings contain considerable reference to the nature of humanity and society, implicitly recognising the need to revise modern anthropological assumptions and use them as a grounding for economic thought. Part of the reason his work has been passed by is that it appeals to dimensions of human action that are invisible to conventional economists of either stripe. 


\section{THE ANTHROPOLOGICAL DIMENSION}

A major opportunity for Western thought emerging from globalisation is the humbling recognition that its anthropology may be deficient, that other cultures thrive using completely different understandings of what it means to be human.

For each choice of anthropology, there is a potential range of choices of public institutions. This overcomes the modern limitation of trying to condense political possibilities to the narrow line between the political left and right. Left and right, as understood by Western minds, are not meaningful for people who accept a different anthropology. Likewise, it is improper to attempt to use these categories to interpret the institutions of non-Western people who operate within an entirely different anthropology.

This means that the ideological categories of Left and Right that are familiar in the West are not applicable to societies that are based on a different understanding of the human person, even though they may display empirical resemblances to comparable Western institutions. It is well known that customary people generally hold property on a communal basis, but this definitely does not mean that they are socialists. Likewise, economic historians have long debated whether property in ancient Greece was private or not. On one hand, it belonged to individual families for their private benefit, with the family head as the recognised private owner, while on the other, individuals within families, including the patriarch, had very limited personal rights to it. The correct conclusion is that property in ancient Greece lay outside the range of possibilities available to Western modernity.

Given the number of possible distinct anthropologies, including the various customary peoples, several Christian, a number of other major world religions and their variants, as well as the secular Enlightenment ${ }^{2}$ modern perspective, a plurality of political/economic systems is possible. Comparisons between these may not be straightforward, despite apparent similarities. Since Western people tend to give preference to measurable apparent factors, it is the institutional dimension that is emphasised in Western thought. By contrast, indigenous peoples tend to stress the importance of tribal/community values, that is, their anthropological position. The fact that these two groups tend to give prominence to entirely different dimensions in human action may be one of the important factors that serve to block effective intercultural communication. This is especially apparent in the area of the customary title debate.

\footnotetext{
${ }^{2}$ While many Christians may be comfortable with the major tenants of Enlightenment anthropology, strictly speaking, the Christian position cannot accept that spiritual belief is fundamentally subjective with no capacity to inform public policy. Other religious traditions are more set on the matter.
} 
Enlightenment anthropology assumes a material, self-interested, individualistic notion of humanity, whereas customary peoples tend to understand humanity in terms of connectedness through family and clan bonds, where the person exists to contribute to the flourishing of the community, be it family, tribe or nation. Some Western people adopt anthropologies inspired from different sources. The Enlightenment anthropology has spawned a variety of others, such as those of Hegel and Marx, while it was itself largely developed from the Protestant Christian anthropology initiated by Luther and Calvin. Weber (1974) demonstrated how that position facilitated a particular political/economic outlook that was given a philosophical grounding in the eighteenth century. A distinct concept of the human person, also linked to Christian tradition is found in Catholic social thought. This anthropology is linked to the earliest Christian thought, though it tends to be most accessible within a series of papal encyclicals spanning the last century known as the social teachings of the Church. Contemporary Western culture therefore consists of a plurality of positions regarding the nature of the person. A number of distinct anthropologies may also be identified within non-Western peoples, providing a great variety of possibilities.

The Western dichotomy of capitalist/socialist begins to look very limited when it is recognised that it only strictly applies within the Enlightenment anthropology. The institution of property is intimately connected within this question of the universality of the private/common capitalist/socialist dichotomy of political/economic systems. Within some anthropologies, institutional systems can develop that display superficial similarity to the institutions of property found in modernity. Mainland Australian aboriginal land ownership could be interpreted as communal, or if pressed, socialist. Murray Island customary land ownership could be interpreted as private. Eddie Mabo's claim to his land was on the basis that he could identify its boundaries and demonstrate how his family had continuous connection to it within a socially sanctioned land ownership system. However, Eddie Mabo would be appalled to have his title considered as private property in the capitalist sense and mainland aboriginals would not consider themselves as socialists. Customary property may appear to resemble the private property of capitalism or the collective property of socialism, but to draw those conclusions is to ignore much of the dynamic of customary culture and its institutions. Neither group cited use their property in ways that parallel the respective Western institutions.

European feudalism is another instance of property that does not fit neatly into the modern dichotomy. In one sense, it was private property, but only for the king. In another, it was collective property with the king as caretaker. Much depended on the ethical character of the king, but the system itself had qualities of both private and social property, open to the potential benefits and shortcomings of both. European feudalism flourished within a particular version of Christianity and 
tended to abate as the local theology was transformed. Much depended on the ethical stamina of those in positions of power.

An individual's theory of humanity and society will influence personal behaviour directly. The majority of human action is not determined by government sanction, but by personal choice. The decision to greet someone or not, and the decision to set a tender price as high as the market will bear or as low as will cover normal costs are only two examples of the multitude of human exchanges that are not determined by public policy. Thus, the anthropology adopted impacts on our confidence and comfort in dealing with others and underpins our ethical and social profile. The challenge in sales is to convey an aura of trustworthiness while not neglecting the modern preoccupation with profit maximisation. The self-interested individual that is homo economicus may be a sound manifestation of the Enlightenment anthropology, but he hardly inspires trust when encountered on the other side of the negotiating table. It was with this in mind that Weaver (1948, p.556 ) concluded that his age had exchanged the gangster for the gentleman as moral exemplar for modern culture.

Enlightenment anthropology has had a long history of difficulty with trust. Human history bristles with instances of humans acting in antisocial ways that led Hobbes to conclude that humans were naturally warlike. He posited a rational calculus made within every person to accept the yoke of civilisation, not due to its latent attraction, but as a strategy for participating in the superior level of welfare that it provided. Rousseau reversed Hobbes's pessimistic appraisal of human nature and laid the blame for human frailty at the feet of society. In his view, people were born virtuous, but quickly learned anti-social traits from social contact. Rousseau's solution was to free people as far as possible from the influence of social traditions and values to let them make their own choices. The result or course was anarchy, but it is a view that is still popularly received.

Four sources appear to be available for trust and related habits. The most obvious is tradition, the most persistent are family bonds, the third is religion and the last is reason. None of these appear to be totally reliable. Zimmerman (1947) demonstrated that the rise and fall of cultures are linked to changes in the nature of the family, suggesting that there is a recurrent sociological trajectory that links values pertaining to family and tradition to cultural growth and decline. Some cultures hold traditions, such as cannibalism, that are generally considered faulty. Family bonds usually work well within the family, but say little for the treatment of outsiders. Some religions, such as the Hindu cult of Kali, recommend abusive treatment of others. Every anti-social act done by a sane person demonstrates the unreliability of human reason as the source of trustworthiness. This is doubly apparent when the antisocial acts are also illegal. To isolate human reason is difficult, since everyone believes that their actions are the result of reason, even if 
their premises are dominated by elements of tradition, family, religion or passion. The only instance of pure reason is philosophy, and its first major task is to establish the degree to which it can operate independent of tradition, family and theology. Even within philosophy, there are many schools, most built on wellrecognised logical or factual flaws and many are transparently little more than instrumental techniques for justifying what would otherwise be unacceptable ethical outcomes. Despite this, Enlightenment thought was over-critical of the shortcomings of the first three, but over-optimistic about reason. It has no formal place for tradition, family, or religion, only human reason.

Each of these four factors could also be taken as further dimensions of human action in their own right. While they inform a person's anthropology, they also directly govern human action in their own realms. For the present purpose, only religion, or spirituality, will be considered. Religion, or spirituality, is distinct in that it relates to transcendent realities and is commonly cited by customary peoples when discussing property. On the other hand, tradition could be considered as no more than a conglomeration of historical forces, and family bonds could be dismissed as moderately self-evident. Finally, reason has been discussed as a common factor in all human deliberation, so it ceases to be an active dimension, given that only rational behaviour is being examined.

\section{THE SPIRITUAL DIMENSION}

The spiritual dimension deals with the non-material in a way that affects human action. It also makes an important contribution to the human understanding of property. A person's spirituality impacts on action regarding property in two ways. Firstly, it informs the problem of the root of title to land and secondly, it informs the question of the nature of humanity and its ethical parameters.

The major problem with the notion of property is that it cannot be attributed to an intelligent producer in the way that personal property, e.g. intellectual property, is. Most religions include a genesis story that attributes the creation of the world to the personal action of some spiritual being. Philosophically, this is a necessary conclusion since all material things are contingent, they are the product of other material things and forces, but the regress of causality cannot be infinite amongst material things. There must exist a being whose nature is not contingent and who is capable of giving being to things that would otherwise be non-beings. That is, there must exist at least one non-material being that is capable of creating the material things that comprise our world. In some traditions, there are many such spiritual beings, in others, there is only one. The important thing for property is that land property naturally is owned by its creator/s. If the creator/s have some intelligible relationship with human society, then land property will feature as part of that 
relationship. Most customary peoples adopt spiritualities that explain the origin of their land property and set out principles for its licit administration (Small, 1997).

In most spiritualities, the relationship between the spiritual beings and humanity is social. The spiritual beings always have some initial relationship with the world and is people and usually take an ongoing interest in human action, offering direction to humanity, hearing their supplications, offering support but sometimes also punishment. In terms of direction, the spiritual beings tend to provide both general principles for moral action and in some cases, specific guidelines for public policy. Christianity, Islam, Judaism and customary religions all contain direction regarding the institution of property. They also convey notions of humanity that contribute to the distinctive anthropologies of the various spiritualities. Thus, in Christianity, humanity is understood to be a single family under a single loving spiritual Father, whereas under Islam, the headship relation is more in terms of submission to the will of Allah which includes a moral code that determines relations between Moslems as well as the treatment of non-Moslems. Customary spiritualities often place the creator spirit/s as the head of the tribe in a way that distinguishes between moral duties to tribe members and duties to outsiders.

The various positions on spirituality can be reduced to three categories; positive, negative and atheist. Most religions assert that they exist to serve what could be called a positive deity, or deities. By positive is meant that the deities value goodness as commonly understood and shun evil. A positive deity could be expected to encourage charitable relations between persons that could be manifest in the responsibilities of property. In Islam, property wealth is expected to be used in part for charitable purposes, such as alms giving (Nomani and Rahnema, 1994). Christianity has similar traditions (Ederer, 1995) ${ }^{3}$. Most customary peoples link their cultural commitment to the material welfare of their people through the use of their land property to their spirituality. In this way, the spiritual dimension provides a direct influence on human action, even regarding property.

Conversely, some deities relate to humanity as angry and vengeful beings that demand sacrifice and rule through fear. These spiritualities are conspicuously negative, at least in the common assessment. The Indian Thuggies, who served the Hindu god Kali, practiced murder and violence as religious observance. Other examples include the ancient Phoenicians and the Aztecs. The point here is that these spiritualities operated on relations between people that are generally repugnant, utilising fear, violence and oppression. The possibility exists that spiritualities such as these, if they included links to property, could be expected to promote the use of property for exploitation and injustice.

${ }^{3}$ See Aquinas (1981) on private property. 
The third group within the spirituality dimension is the atheist or materialist spirituality. While this may not be a spirituality strictly speaking, it has the same impact as a spirituality and is what is referred to in sociology as a functional equivalent to religion. The atheist believes that there is no extra-material cause to the material universe and its existence is simply a given that will eventually be explained using physical laws. This frees the atheist from any essential ethical obligation regarding property and can be seen as underpinning the theories of property from Smith's Enlightenment onwards. Property has been moving in this direction in the West for half a millennia and it has given rise to the modern possibilities of both communism and capitalism. Both of these have enjoyed both limited success and failure.

Given that historical choices regarding spirituality have had varied results, conclusions regarding the most useful spirituality for effective administration of property may be appropriate. This may require a revisiting of the objects of economics. If economics is about achieving the best material outcome for a society, then this objective is broadly comparable to the asserted goals of many positive spiritualities. As it is, customary people are being prompted to abandon the material precepts of their spiritualities on the basis that it will return them a superior material outcome. Obviously, these questions require careful consideration of exactly what constitutes optimum material outcomes and what other values should be considered.

\section{CONCLUSION}

The way forward in property is to broaden the perspective of analysis beyond the limited belief that property institutions lie somewhere on a single ideological continuum between the Left and Right. This paper has argued that in addition to the ideological dimension that governs public institutions familiar in Western thought, there are several other dimensions to human action that impact on property. In particular, these include the anthropological dimension and the spiritual dimension that have been discussed here.

It has been shown that the institutional dimension rests on the choice of anthropology that in turn relies on spiritual beliefs, even when the latter is the belief that there is no spiritual dimension. To understand property, especially as it exists and is practiced in various cultures, requires due recognition of these other dimensions. In particular, in discussions regarding customary title, more emphasis may be warranted on these other dimensions.

Pacific Rim Property Research Journal, Vol 9, No 4 


\section{REFERENCES}

Aquinas, T. (1981), "Summa Theologica". Westminster, Merryland, Christian Classics.

Cuff, E. et al. (1990), "Perspectives in Sociology”. London, Unwin Hyman.

Ederer, R. (1995), “Economics As If God Mattered”. South Bend, In, Fidelity Press.

Ezigbalike, I. (1994), "Cadastral "Reform" - At What Cultural Costs to Developing Countries". The Australian Surveyor 39 (3): 177-186.

Johnson, P. (1995), "Reason in the Balance”. Downer's Grove, Il, Intervarsity.

Hume, D. (1777/1975), "Enquiries Concerning Human Understanding and Concerning the Principles of Morals". Oxford, Claredon.

Macpherson, C. (1978), "Property: Mainstream and Critical Positions". Toronto, Toronto University Press.

Nomani, F. and Rahnema, A. (1994), "Islamic Economic Systems". London, Zed.

Roepke, W. (1937/1994), "Economics of the Free Society”. Grove, PA, Libertarian

Roepke, W. (1948/1996), "The Moral Foundations of Civil Society". New Brunswick, Transaction

Small, G. (1997), "A Cross Cultural Economic Analysis of Customary and Western Land Tenure". AIVLE: The Valuer(August).

Smith, A. (1778/1910), “The Wealth of Nations”. London, J. M. Dent.

Weaver, R. (1948), "Ideas Have Consequences". Chicago, University of Chicago Press.

Weber, M. (1974), “The Protestant Ethic and the Spirit of Capitalism". London, Allen \& Unwin.

Devlin, P. (1965), “The Enforcement of Morals". Oxford, Oxford University Press.

Zimmerman, C. (1947), "Family and Civilization”. New York, Harper.

Pacific Rim Property Research Journal, Vol 9, No 4 